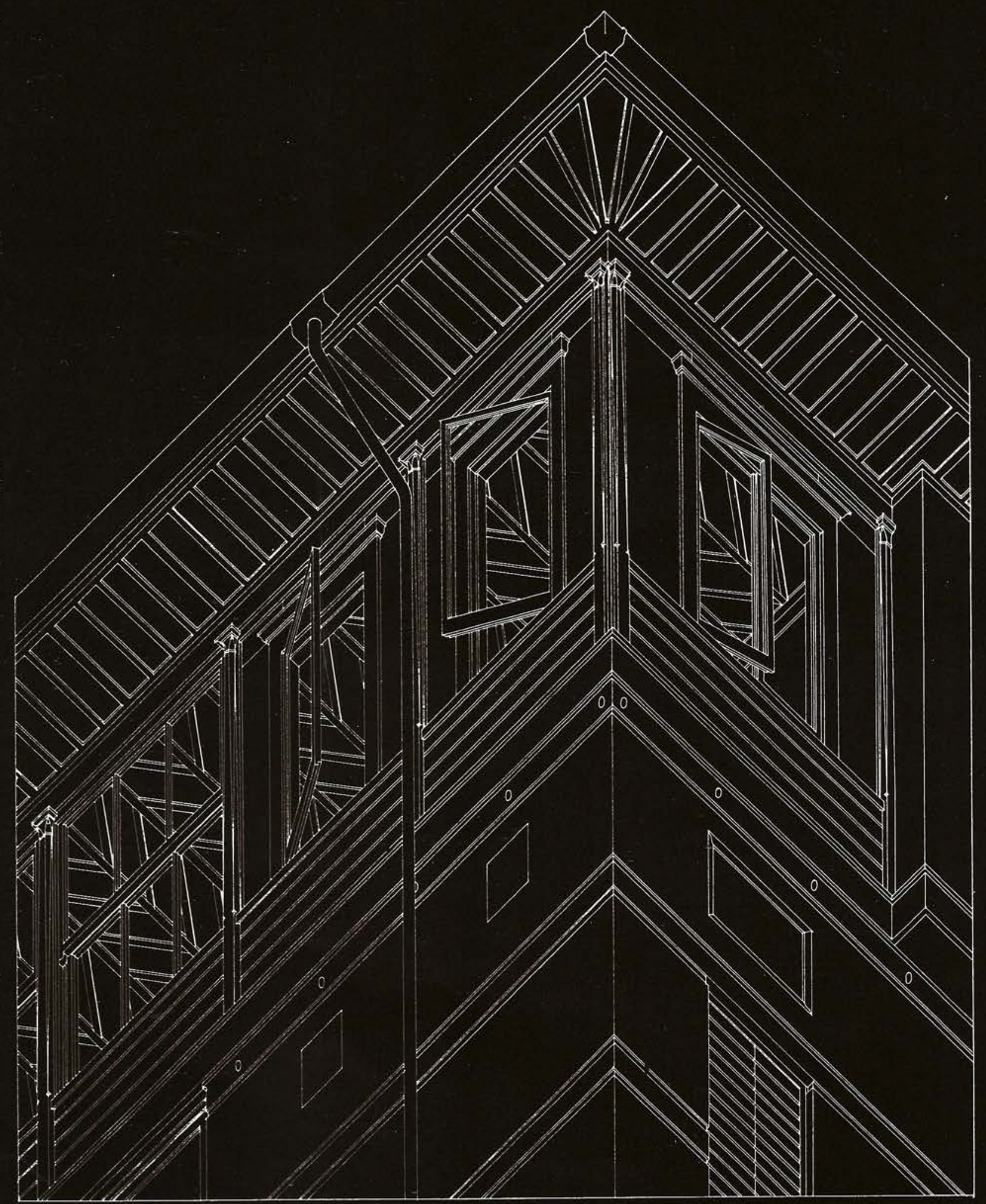




\section{Two Houses at Haslett Street, Eden Terrace, Auckland, 1989-90}

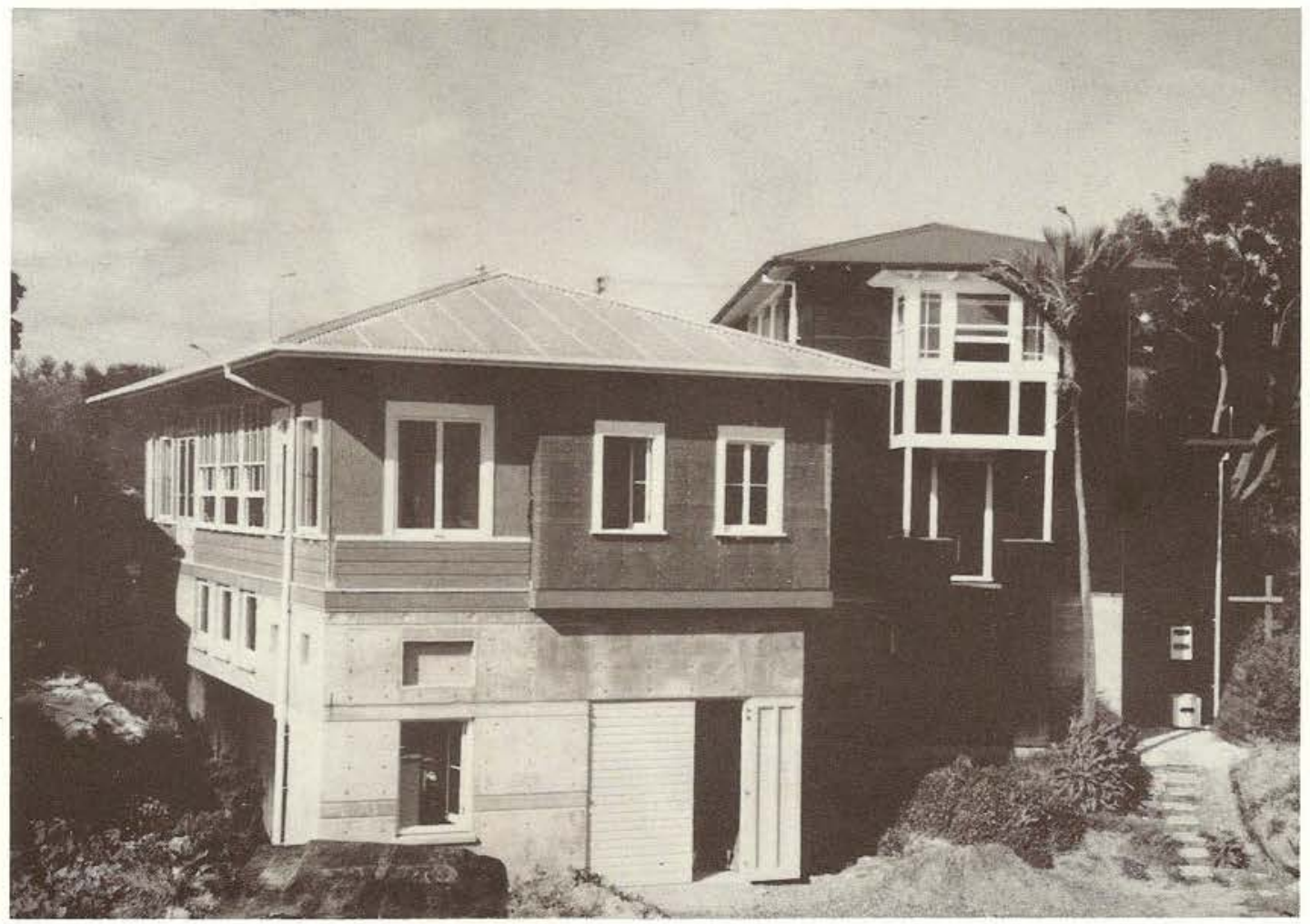

Neil Kirkland and Kim Sinclair graduated from the School of Architecture, University of Auckland, Fractice Architectural Design and Construction in Auckland. They have completed a number of private dwellings.

Sinclair and Shouler House Design: Kim Sinclair Builders: Neil Kirkland and Kim Sinclair

Kirkland House

Design: Neil Kirkland Builders: Neil Kirkland and Kim Sinclair

opp. Worm's eye isometric of Nor-Western corner of Kirkland House

View from Haslett Street (West). 


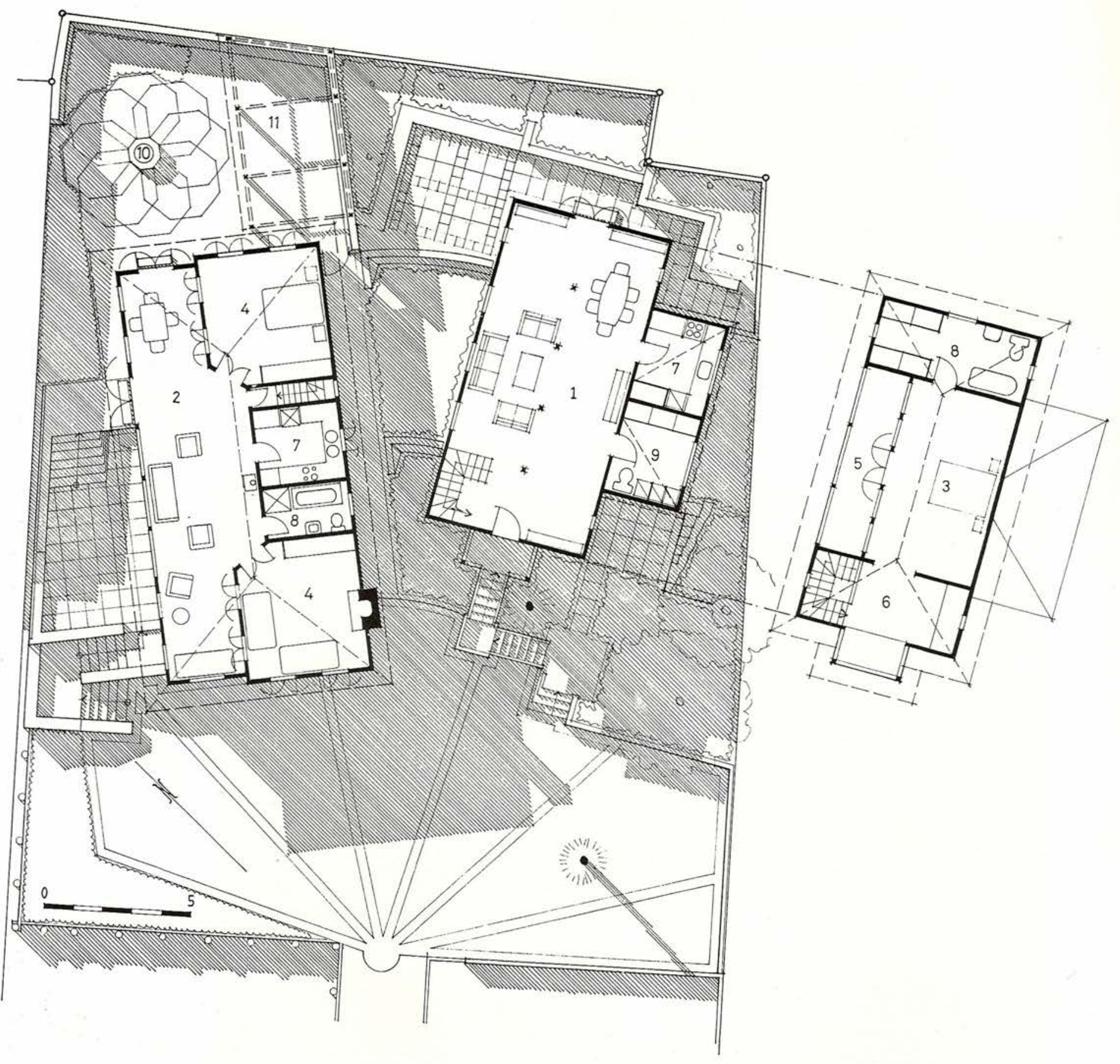

Plan

Legend

1. Living Room

7. Kitchen

2. Sofa (Hall)

8. Bathroom

3. Bedroom

9. Laundry

4. Oda (Rooms)

10. Fountain

5. Loggia

11. Pergola

6. Study 


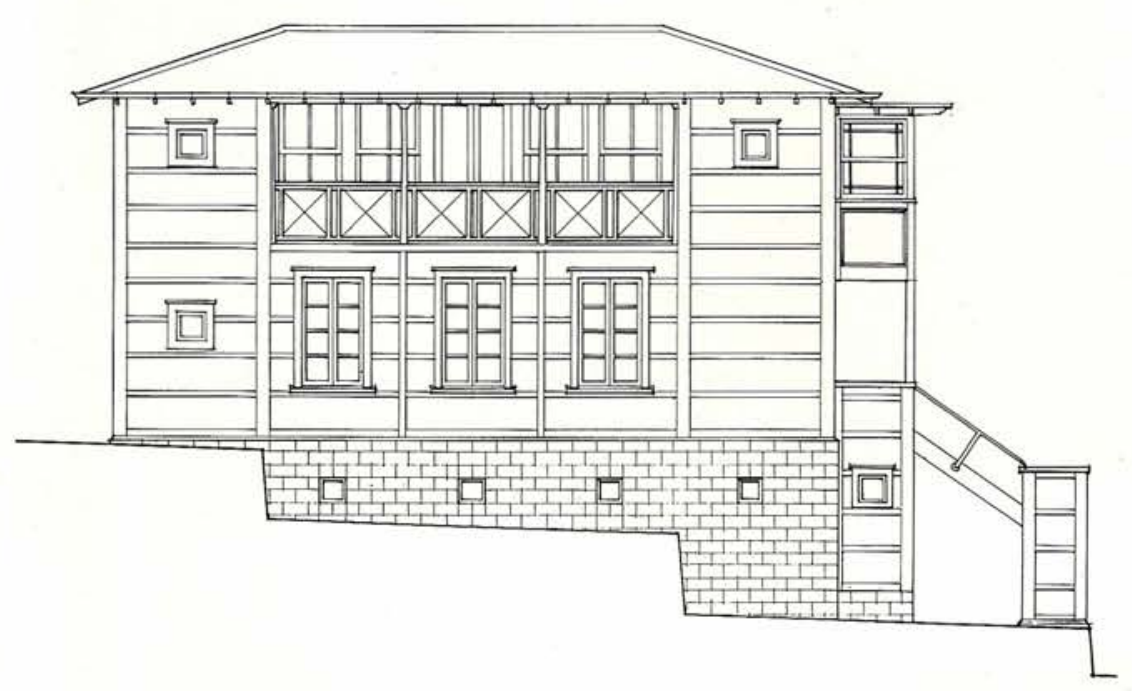

Sinclair and Shouler House: North Elevation

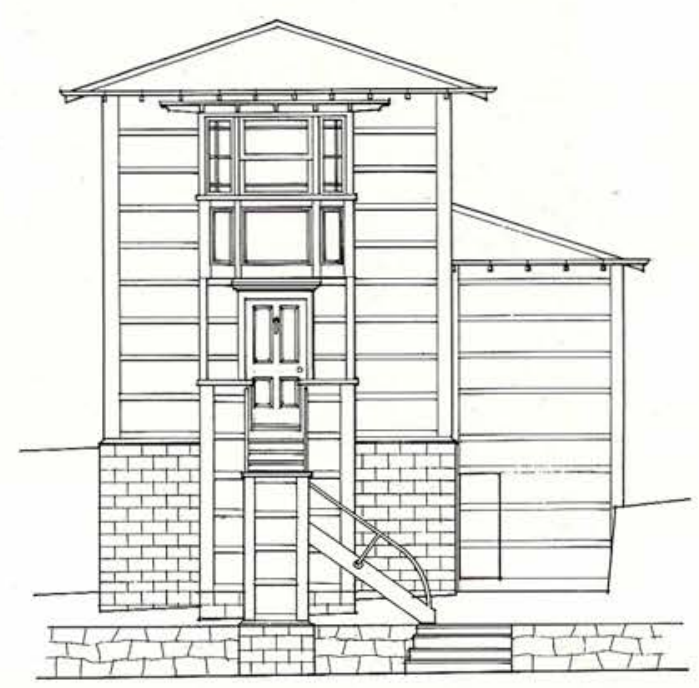

Sinclair and Shouler House: West Elevation

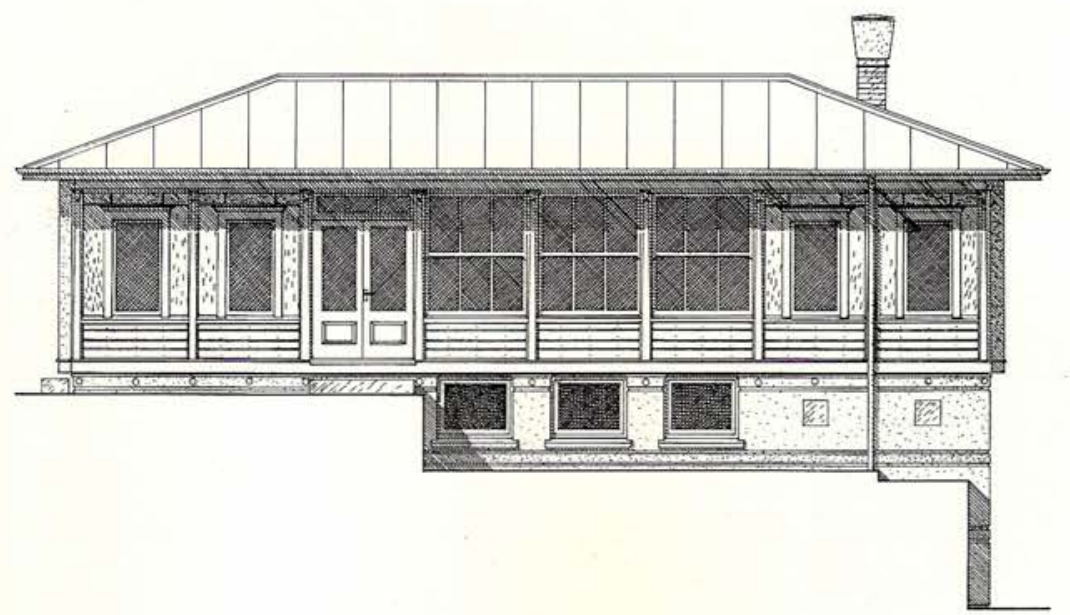

Kirkland House: Nor-West Elevation

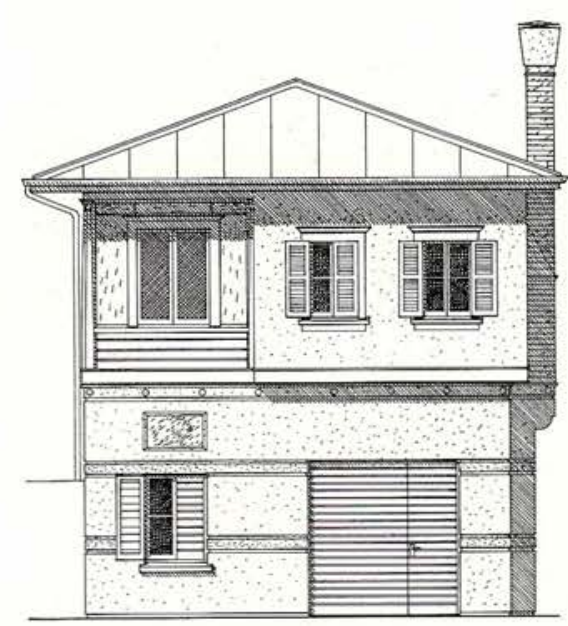

Kirkland House: Sou-West Elevation 


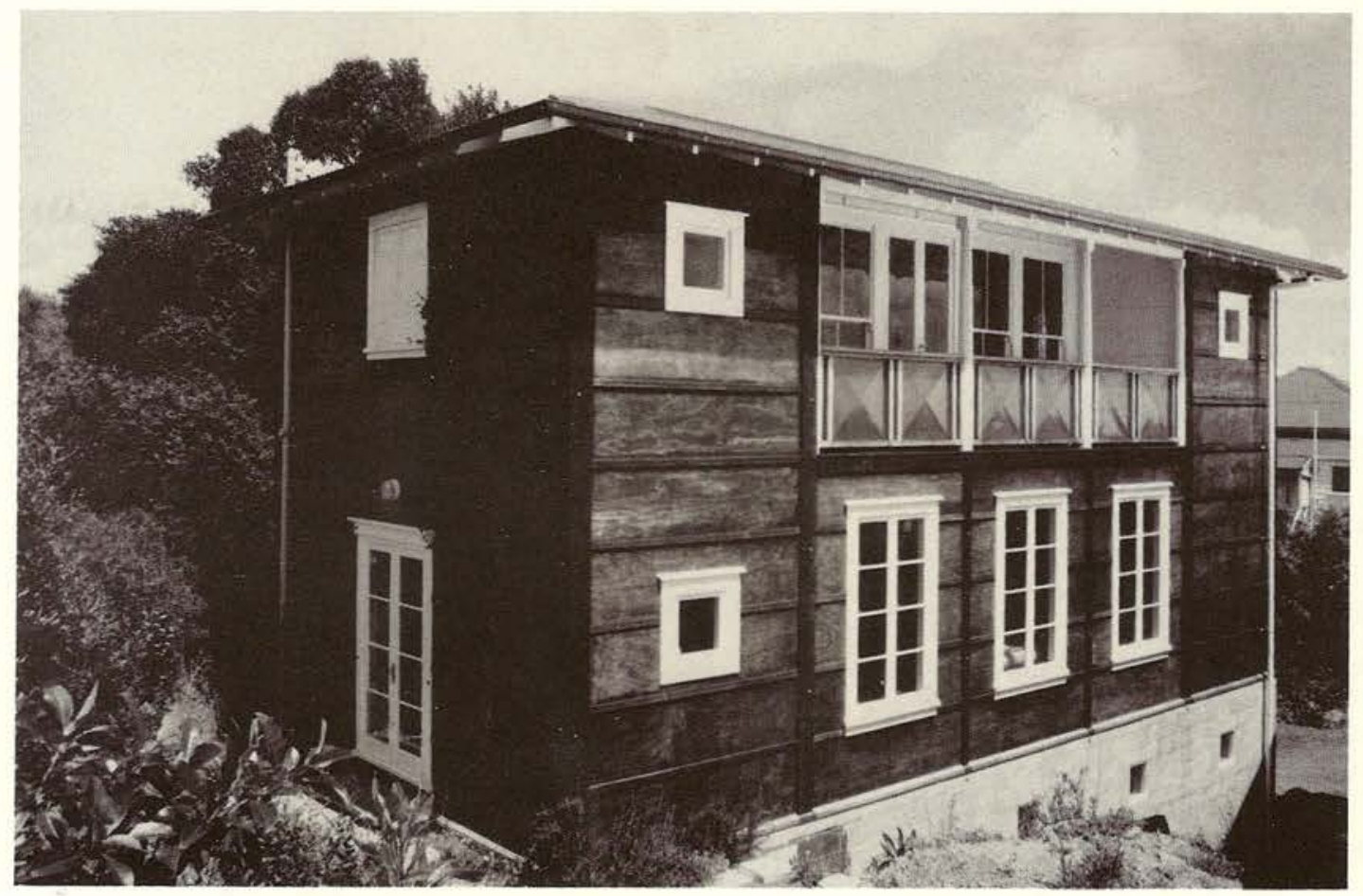

Sinclair and Shouler: Bedroom and on to Loggia

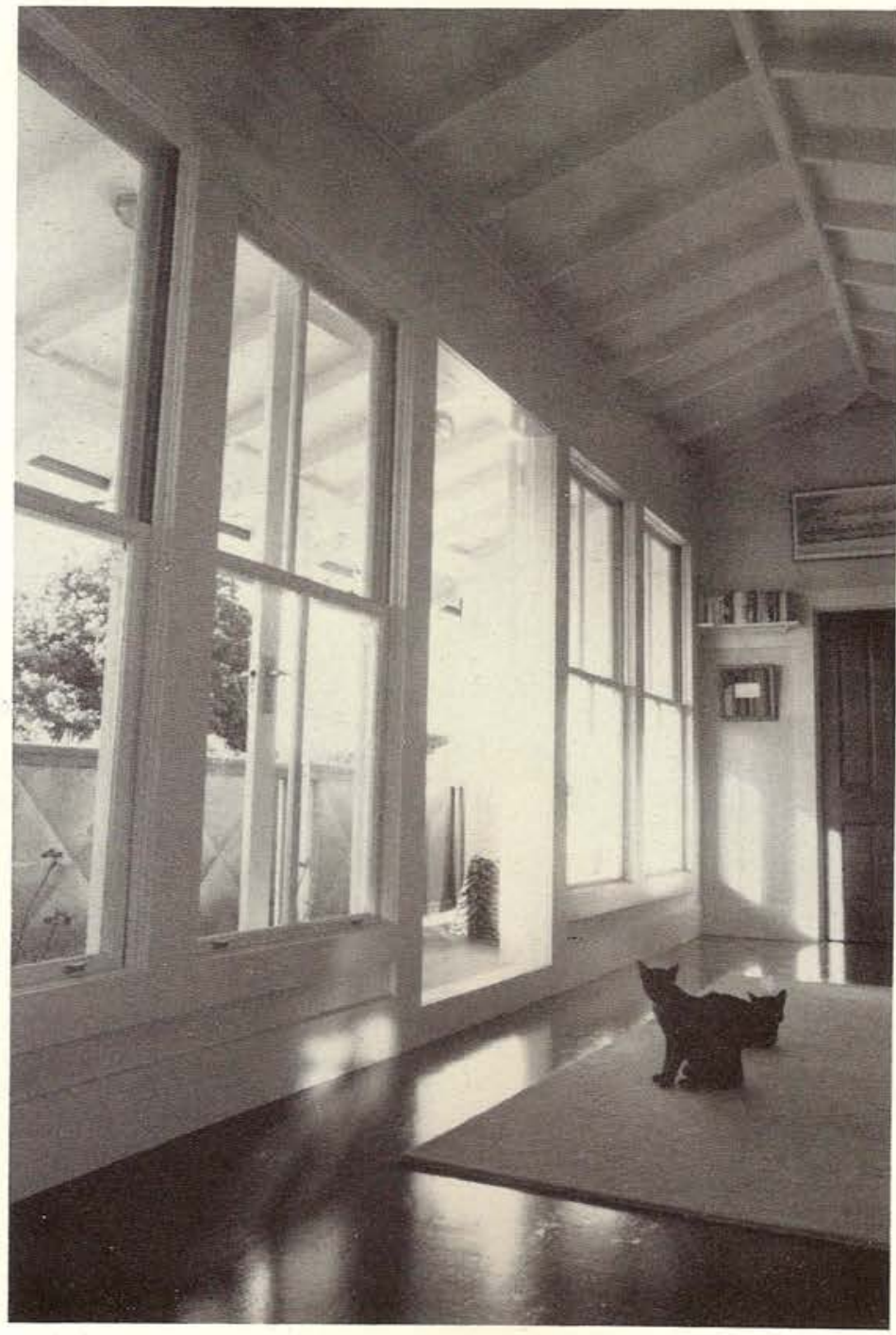

Sinclair and Shouler: View from Nor-East 

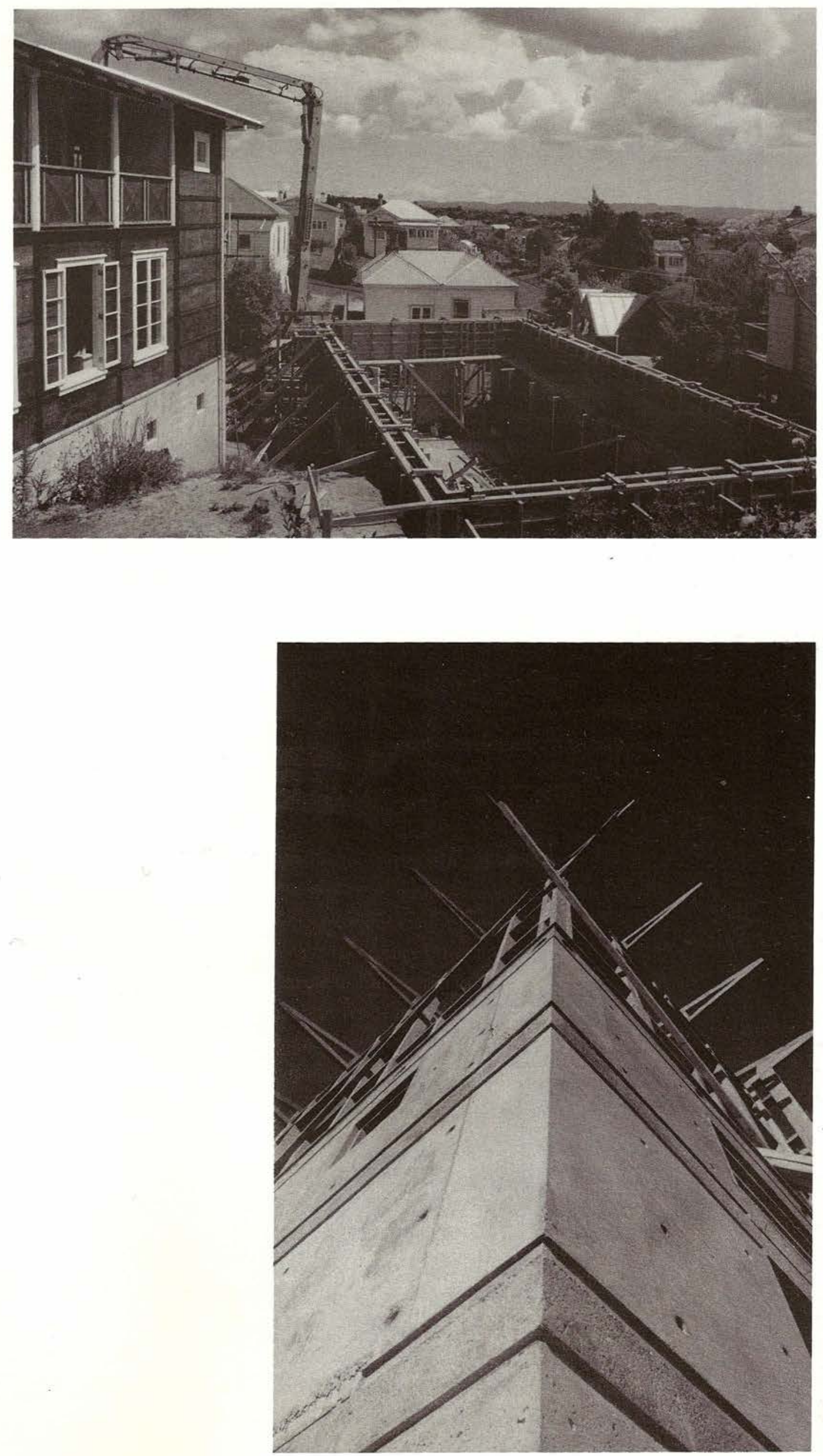